\title{
Conversion of bagasse to char-water fuel by pyrolysis
}

\author{
G. J. Griffin, L. C. K. Tan, L. K. Ho \& M. Pannirselvam \\ School of Civil, Environmental and Chemical Engineering, \\ RMIT University, Australia
}

\begin{abstract}
The purpose of this research was to study the conditions that maximize the formation of char when sugar cane bagasse (SCB) is pyrolysed. It has been proposed that char produced from biomass may be crushed and then suspended in water to produce a char-water fuel suitable as a heavy oil replacement. Experiments were conducted by thermal gravimetric analysis (TGA) and Fourier transfer infrared spectrometry (FTIR) to measure the effect of the chemical additives diammonium phosphate (DAP) or monoammonium phosphate (MAP) on the mass-loss processes of SCB when heated between $100^{\circ} \mathrm{C}$ and $700^{\circ} \mathrm{C}$ under nitrogen. The additives were impregnated on the SCB as aqueous solutions at concentrations of between $0.01 \mathrm{M}$ and $1.0 \mathrm{M}$. For untreated bagasse, char yield was $18 \mathrm{wt} \%$ at $400^{\circ} \mathrm{C}$ and $16.5 \mathrm{wt} \%$ at $700^{\circ} \mathrm{C}$. For treated $\mathrm{SCB}$, it was observed that the additives initiated mass loss at lower temperatures and produced significantly larger yields of char than untreated bagasse. When heated to $450^{\circ} \mathrm{C}$, the char yield increased with additive concentration. If heated above $450^{\circ} \mathrm{C}$, another mass loss occurred between $450^{\circ} \mathrm{C}$ and $600^{\circ} \mathrm{C}$, but only for those $\mathrm{SCB}$ samples treated with additives at concentrations greater than $0.1 \mathrm{M}$. Thus, when heated to $700^{\circ} \mathrm{C}$ the maximum yield of char occurred for SCB sample treated with $0.1 \mathrm{M}$ additives. Analyses of the evolved pyrolysis gases using FTIR showed that treated $\mathrm{SCB}$, at concentrations greater than $0.1 \mathrm{M}$ DAP or MAP, contained less hydrocarbon species and were enriched in water consistent with the catalytic degradation of the SCB. When treated with higher concentrations of additives, gases that evolved at temperatures above $450^{\circ} \mathrm{C}$ were rich in phosphoric acid esters and aromatic and unsaturated phosphonic acid species. Keywords: pyrolysis, bagasse, bio-char, catalyst, TGA, FTIR.
\end{abstract}




\section{Introduction}

Sugar cane bagasse (SCB) is considered the largest source of lignocellulosic, waste agricultural material in the world [1]. SCB is the fibrous residue produced after the extraction of sugar juice during cane milling. For every 1 tonne of cane crushed in a mill, approximately $150 \mathrm{~kg}$ (dry basis) of SCB, is produced [2]. About $70 \mathrm{~kg}$ of this bagasse is needed for combustion in mill furnaces to produce steam and energy to run the mill, leaving an excess of $80 \mathrm{~kg}$ of bagasse. Additional sources of lignocellosic material from the cane are the cane leaves and tops (CLT), which are cut from green cane during harvesting, and cane trash (CT) that is dried leaves shed by the plant during growth. If gathered during harvesting, CT and CLT could contribute another 100 and $70 \mathrm{~kg}$ (dry basis), respectively, of lignocellulosic material per tonne of cane crushed [3]. Global sugar cane production exceeded 1,700 MT in 2010 [4] equating to over $425 \mathrm{MT}$ of available, waste lignocellulosic material.

Considerable research effort is expended on investigating uses for SCB, CLT and $\mathrm{CT}$, especially as a renewable energy source. Most research focuses on either conversion of the fibre to monosaccharide sugars suitable for fermentation to ethanol, or; pyrolysis of the material to yield fuel gases, liquids (biooil) and solids (biochar). Leibbrandt et al. [5] modelled the energy efficiency for SCB to ethanol by fermentation processes, and pyrolysis of SCB to char, synthesis gases and biooil. They found that the pyrolysis route was more efficient (up to $70 \%$ recovery of the energy as pyrolysis product) compared to fermentation (up to $30 \%$ recovery of energy in ethanol and up to $21 \%$ energy recovery via electricity production). However the energy requirements of refining bio-oil produced by pyrolysis were not included in the study. Ellem and Mulligan [6] concluded that pyrolysis of lignicellulosic biomass to char/gas product was more energy efficient than a biomass-to-liquid (BTL) process route. Furthermore they contended that the char could be processed to char-water fuel (CWF) and/or char-hydrocarbon fuel (CHF) which are suitable for use in ship, rail and other transport fuel applications. A clear advantage of using such technology to generate liquid fuels from bagasse is the significant increase in energy density (on a volume basis) of the fuel. SCB is a low-density, fibrous material which typically has an energy density of $\sim 100 \mathrm{~kJ} / \mathrm{L}$, whereas char-water fuels have energy densities up to 100 times as great.

The pyrolysis of SCB shows a strong effect of heating rate, duration of heating and temperature range of heating on the char yields. Thermal gravimetric analysis (TGA) studies [7-10] performed at a constant heating rate show the bulk of mass loss occurs from 200 to $400^{\circ} \mathrm{C}$ with char yields (on an ash-free basis) of about $15-20 \%$ when the temperature exceeds $500^{\circ} \mathrm{C}$. Tube furnace studies $[11,12]$ achieved higher yields at temperatures of $500^{\circ} \mathrm{C}$ and char yields were further enhanced when extremely high heating rates and short heating times were employed, but this was indicative of only partial decomposition of the biomass material rather than a change in the reaction mechanisms. Pretreatment of SCB with soluble chemical additives [7, 13, 14] show that mass-loss events during pyrolysis are initiated at lower temperatures 
and result in greatly enhanced char yields compared to untreated SCB. For example, the use of the chemical additive borax increased char yield (on an ashfree basis), at $500^{\circ} \mathrm{C}$, to $46.7 \%$ [7]. However, the non-volatile nature of such an additive results in high ash content of the char thus making it less suitable as a fuel source. Furthermore, previous studies have not investigated the optimal loading of additives for maximum char production.

The purpose of this study was to investigate the effect of the treatment of SCB with two additives - diammonium phosphate (DAP) and monoammonium phosphate (MAP) - on the degradation kinetics and char yield. These additives were chosen as they are degrade under heating to produce phosphoric acid and phosphorous pentoxide which can initiate thermal degradation of lignocellulosic material at lower temperatures and enhance char production [15]. Furthermore, these compounds are non-toxic and thermal decomposition releases gases that may be recovered.

\section{Experimental methods}

Fresh bagasse, retrieved from Invicta Mill, Giru, Queensland was washed, dried and sieved to produce samples with particle size between 3 and $5 \mathrm{~mm}$. Proximate analysis of the bagasse was $83.7 \%$ volatile matter, $14.3 \%$ fixed carbon and $2.0 \%$ ash. Using the correlation reported by Shen et al. [16], the ultimate analysis of the bagasse is $48.7 \%$ carbon, $6.0 \%$ hydrogen and $44.8 \%$ oxygen. Dried bagasse was immersed in aqueous solutions of $0.01,0.05,0.1,0.5$, or 1.0M DAP $\left(\left(\mathrm{NH}_{4}\right)_{2} \mathrm{HPO}_{4}-\right.$ Sigma-Aldrich, purity $\left.>98 \%\right)$, or MAP $\left(\left(\mathrm{NH}_{4}\right) \mathrm{H}_{2} \mathrm{PO}_{4}\right.$ - Sigma-Aldrich, purity $>98 \%$ ). Based on the amount of solution absorbed, the concentration of chemical additive in the bagasse was $90 \mu \mathrm{mol}(\mathrm{g} \text { bagasse })^{-1}\left(\mathrm{M}^{-1}\right.$ additive). The dried samples were then air sealed.

The mass-loss kinetics of bagasse (with or without chemical additives) was measured by TGA experiments conducted using a Perkin Elmer STA 6000. The experiments were performed over a temperature range of ambient to $700^{\circ} \mathrm{C}$ under laboratory grade nitrogen (flow rate $=20 \mathrm{~mL} / \mathrm{min}$ ) using a constant heating rate of $10 \mathrm{~K} / \mathrm{min}$. The initial masses of the bagasse samples were between 5.0 and $10.0 \mathrm{mg}$ and experiments were conducted using alumina pans. At the completion of each temperature scan the operating gas was switched to air for 8 minutes to oxidise any organic char and provide a measure of the inorganic ash content of the samples.

The gases evolved from the decomposing samples were passed via a heated $\left(250^{\circ} \mathrm{C}\right)$ transfer line to a Fourier Transfer Infrared Spectrometer (FTIR - Perkin Elmer Spectrum 100) in which the gases were scanned continuously (each scan lasted $35 \mathrm{~s}$ ) between 600 and $4000 \mathrm{~cm}^{-1}$ at $4 \mathrm{~cm}^{-1}$ resolution.

\section{Results and discussion}

\subsection{Mass-loss results}

Figures 1 and 2 show differential thermal gravimetry (DTG) plots for bagasse treated with, respectively, DAP and MAP. The rate of mass loss (rml) are 
normalised with respect to the original mass. The DTG plot for the untreated bagasse (solid line) exhibit two major peaks at 308 and $358^{\circ} \mathrm{C}$. Mass loss is initiated at $180^{\circ} \mathrm{C}$. Previous studies [17] indicate that the initial mass loss is caused by degradation of hemicellulose and is responsible for the first observed peak; cellulose degradation occurs at higher temperatures and is responsible for the second observed peak. Lignin degradation occurs over a broader temperature range -200 to $450^{\circ} \mathrm{C}$ [18] - which is evidenced by a 'shoulder' in the curve at $400^{\circ} \mathrm{C}$.

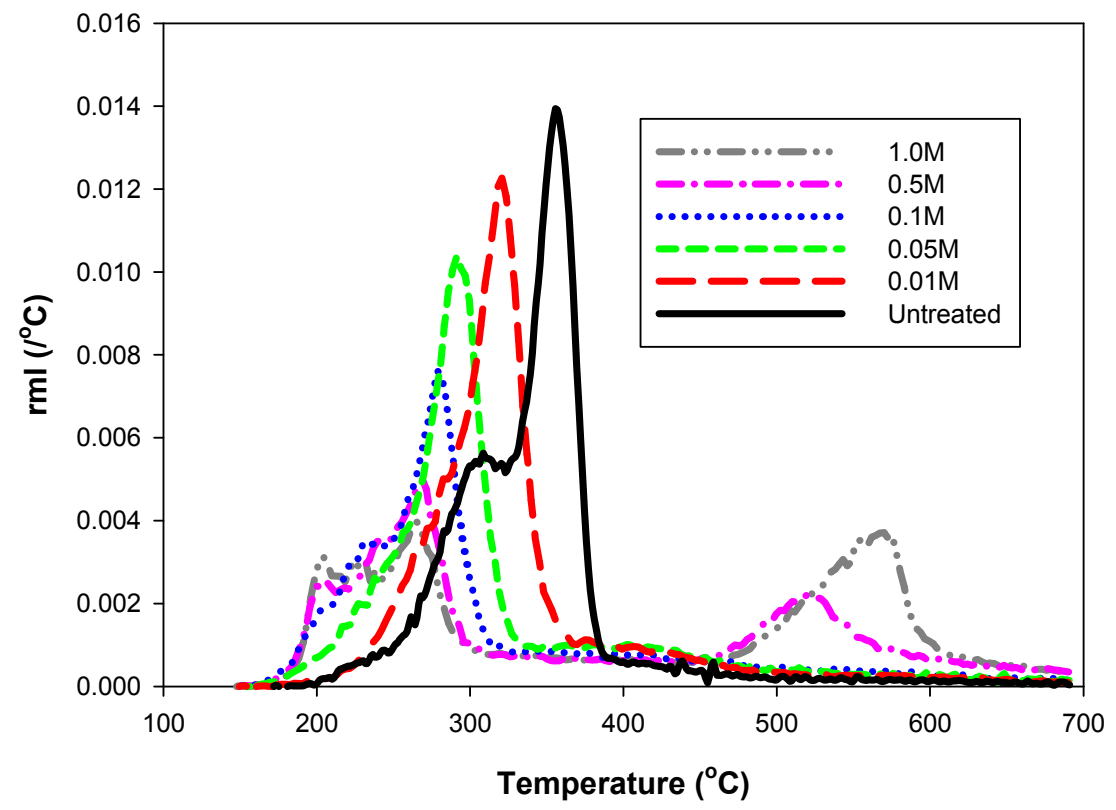

Figure 1: DTG plots for pyrolysis of untreated bagasse and bagasse treated with DAP.

The addition of the DAP or MAP additives shows a marked effect on the kinetics of bagasse pyrolysis. The initiation of mass loss remains at $\sim 180^{\circ} \mathrm{C}$ but the rates of mass loss are increased at temperatures less than $270^{\circ} \mathrm{C}$. At the lowest level of additive addition $(0.01 \mathrm{M})$ the rates of hemicellulose and cellulose degradation are increased at lower temperatures and the two mass-loss peaks merge into a single peak at $318^{\circ} \mathrm{C}$. For higher additive concentrations (i.e. $0.05,0.1$ and $0.5 \mathrm{M})$ the mass loss peak is shifted to lower temperatures $(293,276$ and $266^{\circ} \mathrm{C}$ respectively) and the peak intensity declines as greater proportions of the $\mathrm{SCB}$ are converted into solid char rather than gaseous species. At the highest additive concentration trialled $(1.0 \mathrm{M})$, there is no longer a well-defined peak in mass loss over the temperature range of $180-310^{\circ} \mathrm{C}$. The effect of MAP and $\mathrm{DAP}$ on the degradation of lignocellulosic materials over the temperature range of $180-450^{\circ} \mathrm{C}$ has been attributed to the decomposition of the retardant species 
to ammonia, phosphoric acid and phosphorous pentoxide [15], which takes place at temperatures between 150 and $170^{\circ} \mathrm{C}$. The acid and pentoxide species catalyse the direct dehydration of glucosan units or the dehydration of pyrolysis products levoglucosan [19]. The ammonia species also contribute to the decomposition by reacting with carbonyl compounds.

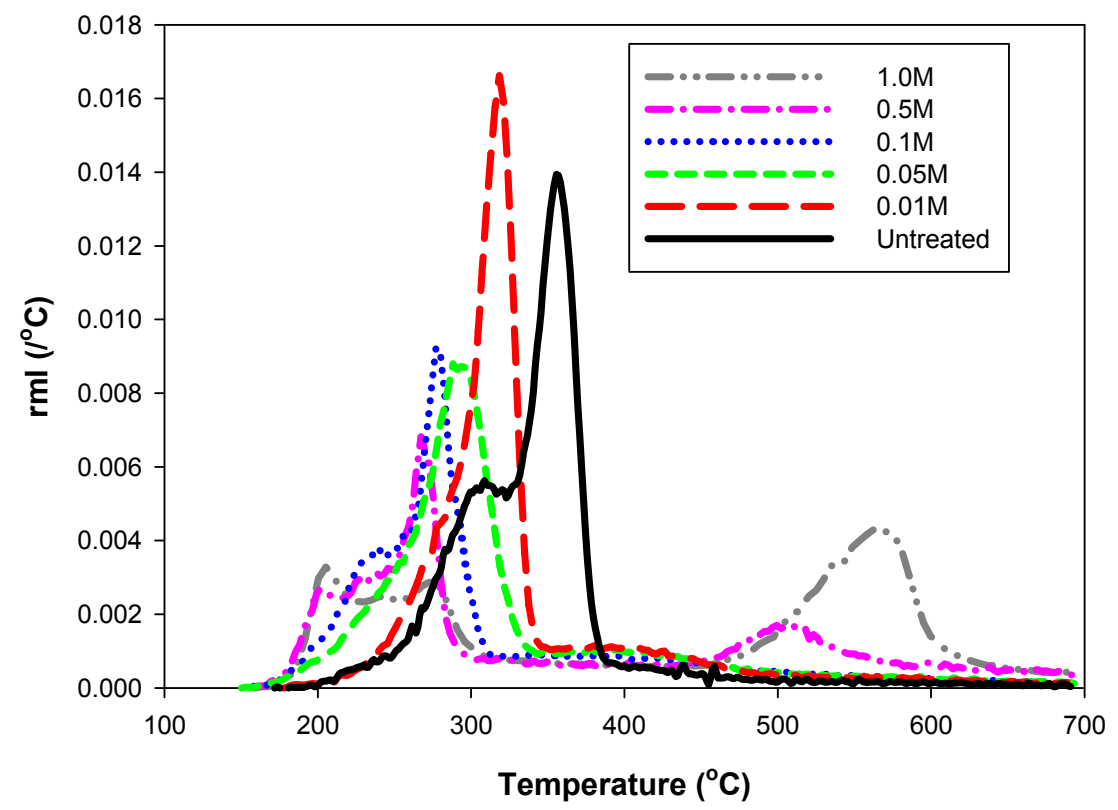

Figure 2: DTG plots for pyrolysis of untreated bagasse and bagasse treated with MAP.

At additive concentrations of 0.5 and $1.0 \mathrm{M}$, a new mass-loss phenomenon is apparent over a temperature range of $450-650^{\circ} \mathrm{C}$, with peak $\mathrm{rml}$ at 500 and $568^{\circ} \mathrm{C}$ respectively. This phenomenon has not been highlighted in the previous literature and is indicative that the presence of high additive concentrations may lead to the formation of new solid-phase compounds that are resistant to thermal degradation. Suardana et al. [20] note that high concentrations of DAP, when impregnated on fibres, results in the formation of water-insoluble condensation products such as phosphorous esters which significantly improves the fire retardant properties of treated bio-composites. It may be inferred from Figures 1 and 2 that the amount of these compounds increases with increasing additive concentration and, consequently, the degradation of these compounds lead to larger mass-loss events at high temperatures.

Figures 1 and 2 show similar mass-loss events regardless of whether DAP or MAP was the additive if the same molar concentration was used to impregnate the SCB. This strongly indicates that the concentration of phosphate ions play a 
much greater role in determining the degradation kinetics than the ammonium ions.

\subsection{Char and ash yields}

Figure 3 shows the total char yields from the TGA trials as measured at $450^{\circ} \mathrm{C}$ or $700^{\circ} \mathrm{C}$. As already noted, at the two highest additive concentrations trialled, a second mass-loss event is observed at temperatures greater than $450^{\circ} \mathrm{C}$. Therefore, when char yields are based on a temperature of $450^{\circ} \mathrm{C}$, the yield increases monotonically with additive concentration. At $700^{\circ} \mathrm{C}$, however, there is a maximum in yield at $0.1 \mathrm{M}$ as at higher concentrations the second mass-loss becomes significant.

Figure 3 also shows the ash yield from the TGA trials measured at $700^{\circ} \mathrm{C}$. Surprisingly, the ash content for additive concentrations above $0.1 \mathrm{M}$ remain relatively constant at between 8 and $11 \%$. This indicates that same proportion of the phosphate compounds is volatile at high temperatures and not retained within the char structure.

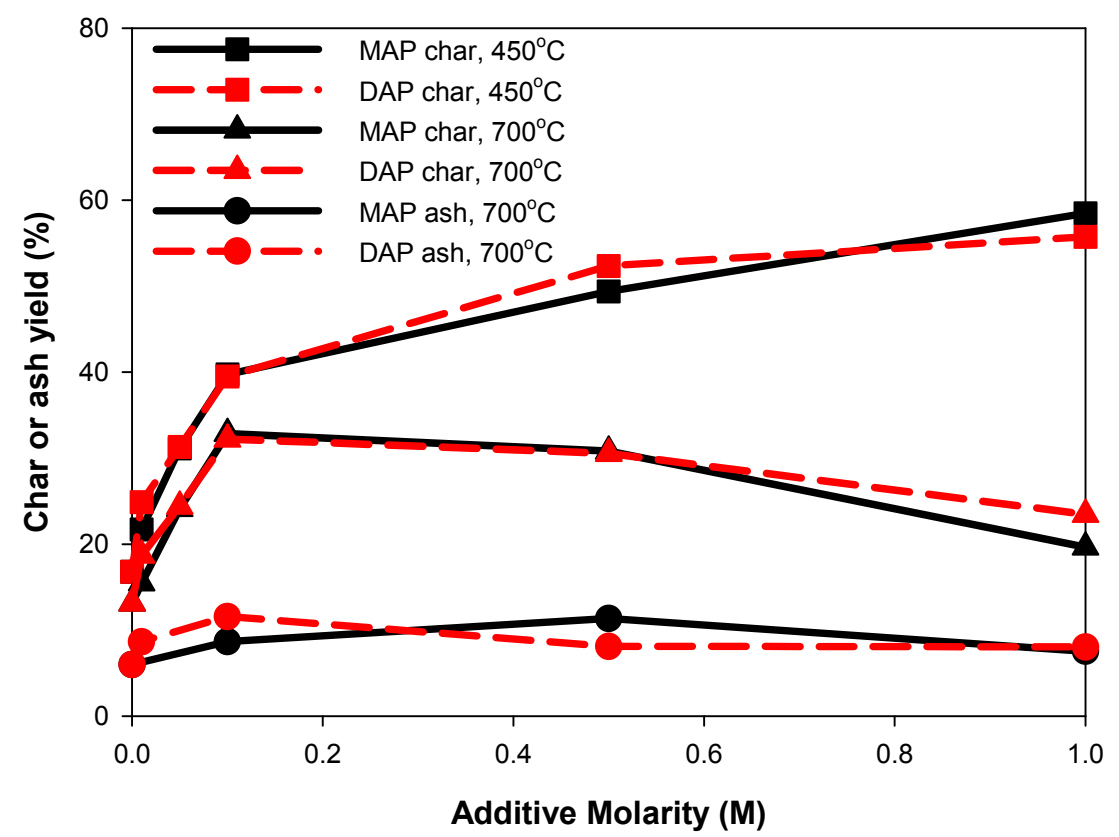

Figure 3: Char and ash yields for pyrolysis of bagasse with varying additive concentration.

Table 1 shows a comparison between the char yields (for $0.1 \mathrm{M}$ additive concentration) from this work with those from previous work [7] using other chemical additives - ammonium sulphate (AS), boric acid (BA) and borax (BX). It can be seen that $\mathrm{BX}$ provides the highest char yield but also the greatest ash 
content due to the non-volatile nature of the additive. In comparison, AS has a relatively low ash yield but also a lower char yield. The ash content of any final char formed has a significant effect on its suitability as a fuel as there are limits to ash content allowed in most commercial fuels, e.g. diesel fuels are usually only allowed ash contents of less than $0.5 \%$. Thus, the higher the ash content of a char the greater processing is required to clean the char with consequent economic penalty.

Table 1: Comparison between char and ash yield for different additives.

\begin{tabular}{|c|c|c|c|}
\hline Treatment & $\begin{array}{c}\mathbf{4 5 0}^{\mathbf{}} \mathbf{C} \\
\mathbf{( \% )}\end{array}$ & $\begin{array}{c}\mathbf{7 0 0}^{\mathbf{}} \mathbf{C} \\
(\mathbf{\%})\end{array}$ & $\begin{array}{c}\text { Ash } \\
(\mathbf{\%})\end{array}$ \\
\hline Untreated & 17 & 16 & 5 \\
\hline 0.1 M Borax & 47 & 42 & 12 \\
\hline 0.1M Boric acid & 31 & 29 & 8 \\
\hline 0.1M Ammonium sulphate & 33 & 29 & 6 \\
\hline 0.1M Diammonium phosphate & 40 & 33 & 8 \\
\hline
\end{tabular}

\subsection{FTIR results for evolved pyrolysis gases}

Figure 4 shows the FTIR spectrum measured for the evolved gases from untreated bagasse at the temperatures of maximum $\mathrm{rml}$ (i.e. $308^{\circ} \mathrm{C}$ and $358^{\circ} \mathrm{C}$ respectively). Absorbance peaks indicative of the presence of $\mathrm{CO}_{2}$ and $\mathrm{CO}$ can be observed in the wave number range of 2200-2400 $\mathrm{cm}^{-1}$ and $2050-2250 \mathrm{~cm}^{-1}$ respectively. Absorbance peaks for hydrocarbon chains are observed in the range of 2800-3100 $\mathrm{cm}^{-1}$. Broad absorbance peaks from the hydroxyl functional groups (3500-3700 $\left.\mathrm{cm}^{-1}\right)$ and ketones/aldehydes functional groups (1650 $1800 \mathrm{~cm}^{-1}$ ) are also apparent. The spectrum indicates the presence of $\mathrm{CO}, \mathrm{CO}_{2}$ and a variety of carboxylic acid, alcohol and aldehydes as evolved gases from the SCB.

Figure 5 shows the FTIR spectrum measured for the evolved gases from bagasse treated with $0.1,0.5$ and $1.0 \mathrm{M}$ DAP respectively. The spectrums were measured at, or near, the maximum rate of mass loss $\left(276,266\right.$ and $266^{\circ} \mathrm{C}$ respectively). The spectrum show a significant reduction in the intensity of the absorbance peaks measured for hydrocarbon groups as the additive concentration is increased. The spectrum measured in the $3500-3700 \mathrm{~cm}^{-1}$ range shows a much finer structure with a series of defined, sharp peaks indicating that water is the dominant chemical contributing to the spectrum over this range. The intensity of the absorbance spectra for $\mathrm{CO}, \mathrm{CO}_{2}$ and hydrocarbon functional groups also decrease indicating a drop in the amount of organic compounds evolved from the SCB and an increase in water evolution. This is consistent with the action of the additive catalyzing the dehydration of the SCB and so increasing the evolution of water and reducing hydrocarbon evolution. 


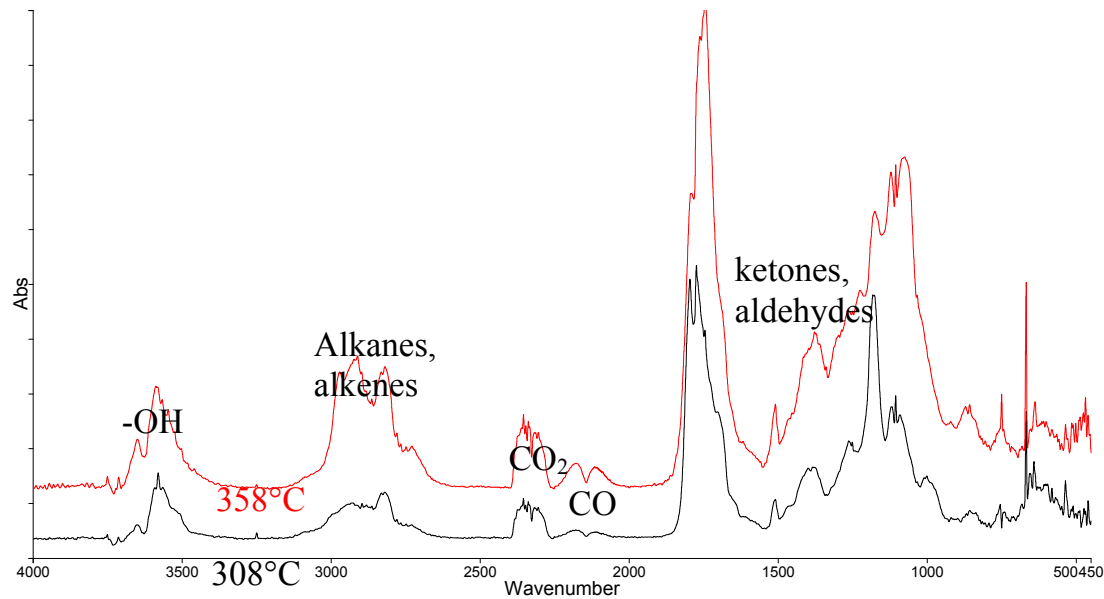

Figure 4: FTIR spectrum for pyrolysis gases evolved from untreated bagasse.

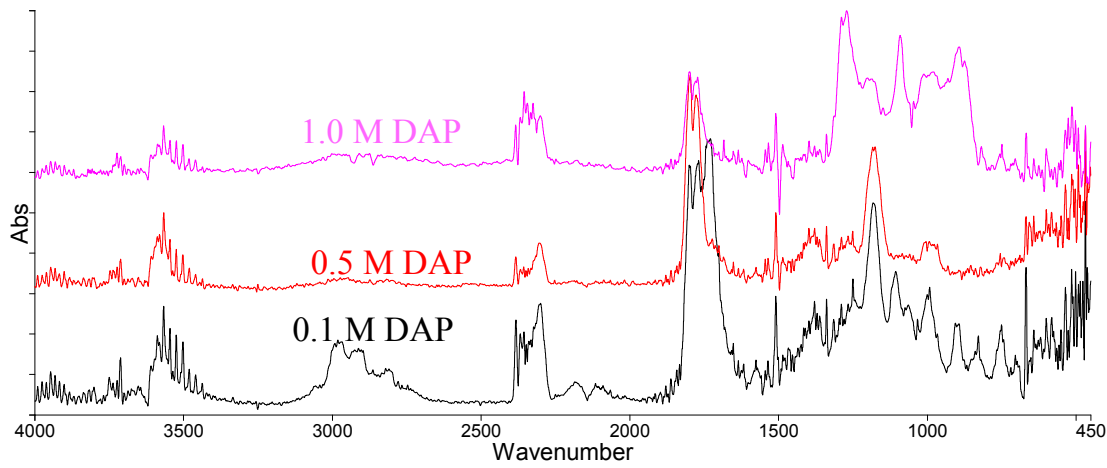

Figure 5: FTIR spectrum for pyrolysis gases evolved from treated bagasse at first mass-loss event.

Figure 6 shows the FTIR spectrum measured for pyrolysis gases evolved during the second mass-loss events for 0.5 and 1.0M DAP treated SCB. The spectrum for $0.5 \mathrm{M}$ DAP treated SCB was performed at $500^{\circ} \mathrm{C}$. Compared to the spectrum for the first stage mass-loss, there is a marked lack in any significant peaks in the $1500-2000 \mathrm{~cm}^{-1}$ region. Absorbance peaks at 902, 950, 1058, 1232, 1410 and $2987 \mathrm{~cm}^{-1}$ are consistent with the spectrum of ethyl, di-ethyl and other organic esters of phosphoric acid. The spectrum of 1.0M DAP treated SCB was measured at $568^{\circ} \mathrm{C}$ (the temperature at maximum rml). The spectrum shows a very broad band over the $2500-3500 \mathrm{~cm}^{-1}$ region which, with the other peaks, is characteristic of phenyl phosphonic acid and similar unsaturated or aromatic phosphonic acids. The spectrum recorded would be consistent with the insertion 
of phosphorous within the cellulose and hemicellulose structure during preparation or during heating of the $\mathrm{SCB}$ and the subsequent evolution of gaseous phosphorous species at temperatures above $450^{\circ} \mathrm{C}$.

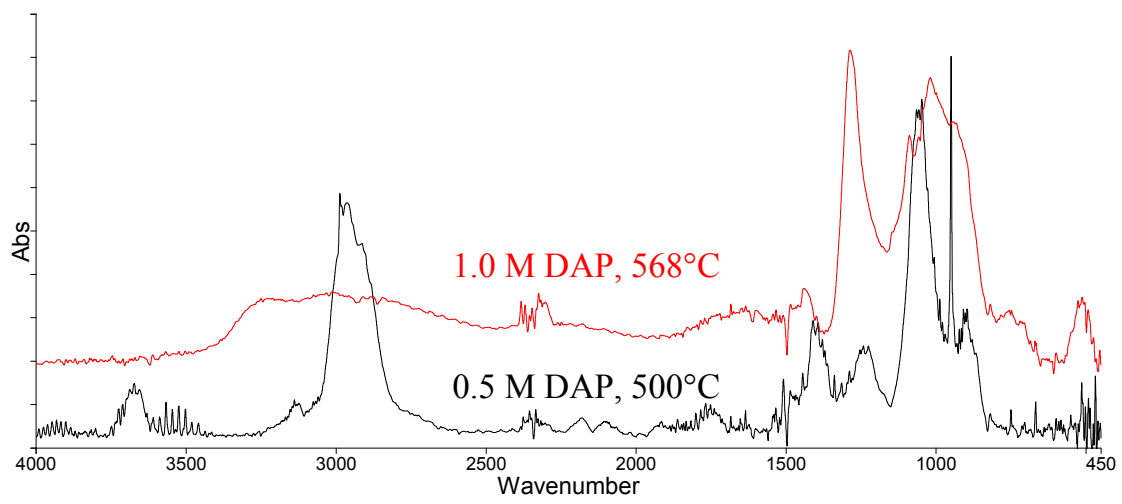

Figure 6: FTIR spectrum for pyrolysis gases evolved from treated bagasse at second mass-loss event.

\section{Conclusions}

The use of MAP or DAP as agents to catalyse and enhance the yield of char from the pyrolysis of SCB has been clearly established in this work. If pyrolysis is conducted up to temperatures of $400-450^{\circ} \mathrm{C}$ then the char yield increases with additive concentration, although the rate of increase in char yield declines at concentrations greater than $0.1 \mathrm{M}$. This improvement in char yield is the result of the action of phosphoric acid and other phosphorous species catalysing the dehydration of the hemicellulose, cellulose and lignin to produce water and reducing evolution of hydrocarbon-based gaseous compounds. If pyrolysis is conducted to $700^{\circ} \mathrm{C}$, however, the char yield may pass through a maximum with respect to additive concentration. At high additive concentration (i.e. $>0.1 \mathrm{M}$ ), the additives may be incorporated into the biomass structure and then evolved as organic - phosphorous compounds at temperatures greater than $450^{\circ} \mathrm{C}$ thus reducing the char yield.

\section{References}

[1] Tuck, C.O., Pérez, E., Horváth, I.T., Sheldon, R.A. \& Poliakoff, M. Valorization of Biomass: Deriving More Value from Waste, Science, 337, pp. 695-699, 2012

[2] Beeharry, R.P. Extended Sugarcane Biomass Utilisation for Exportable Electricity Production in Mauritius, Biomass and Bioenergy, 11(6), pp. 441-449, 1996 
[3] Beeharry, R.P. Strategies for augmenting sugarcane biomass availability for power production in Mauritius, Biomass and Bioenergy, 20, pp. 421429, 2001

[4] FAO, http://faostat.fao.org, 2012

[5] Leibbrandt, N.H., Knoetze, J.H. \& Görgens, J.F. Comparing biological and thermochemical processing of sugarcane bagasse: An energy balance perspective, Biomass and Bioenergy, 35, pp. 2117-2126, 2011

[6] Ellem, G.K. \& Mulligan, C.J. Biomass char as a fuel for internal combustion engine, Asia-Pacific Journal of Chemical Engineering, 7, pp. 769-776, 2012

[7] Griffin, G.J. The effect of fire retardants on combustion and pyrolysis of sugar-cane bagasse, Bioresource Technology, 102, pp. 8199-8204, 2011

[8] Aiman, S. \& Stubington, J.F. The Pyrolysis Kinetics of Bagasse at Low Heating Rates, Biomass \& Bioenergy, 5(2), pp. 113-120, 1993

[9] Munir, S., Daood, S.S., Nimmo, W., Cunliffe, A.M. \& Gibbs, B.M., Thermal analysis and devolatilization kinetics of cotton stalk, sugar cane bagasse and shea meal under nitrogen and air atmospheres, Bioresource Technology, 100(3), pp. 1413-1418, 2009

[10] Ounas, A., Aboulkas, A., El harfi, K., Bacaoui, A. \& Yaacoubi, A., Pyrolysis of olive residue and sugar cane bagasse: Non-isothermal thermogravimetric kinetic analysis, Bioresource Technology, 102, pp. 11234-11238, 2011

[11] Islam, M. R., Parveen, M. \& Haniu, H., Properties of sugarcane wastederived bio-oils obtained by fixed-bed fire-tube heating pyrolysis, Bioresource Technology, 101(11), pp. 4162-4168, 2010

[12] Stubington, J.F. \& Aiman, S., 1994. Pyrolysis Kinetics of Bagasse at High Heating Rates. Energy \& Fuels, 8, pp. 194-203, 1994

[13] Varhegyi, G., M. J. Antal, Szekely, T., Till, F., Jakab, E. \& Szabo, P., Kinetics of the thermal-decomposition of cellulose, hemicellulose, and sugar-cane bagasse, Energy \& Fuels, 2(3), pp. 273-277, 1988

[14] Varhegyi, G., Antal, M.J., Szekely, T \&, Szabo, P., Simultaneous thermogravimetric mass-spectrometric studies of the thermaldecomposition of bio-polymers .2. Sugar-cane bagasse in the presence and absence of catalysts, Energy \& Fuels, 3(3), pp. 329-335, 1989

[15] Liodakis,S., Bakirtzis, D. \& Dimitrakopoulos, A.P., Autoignition and thermogravimetric analysis of forest species treated with fire retardants, Thermochimica Acta, 399, pp. 31-42, 2003

[16] Shen, J., Zhu, S., Liu, X., Zhang, H. \& Tan, J., The prediction of elemental composition of biomass based on proximate analysis. Energy Conversion and Management, 51, pp. 983-987, 2010

[17] Manya, J. J. \& Arauzo, J., An alternative kinetic approach to describe the isothermal pyrolysis of micro-particles of sugar cane bagasse, Chemical Engineering Journal, 139(3), pp. 549-561, 2008

[18] Bilba, K. \& Ouensanga, A., Fourier transform infrared spectroscopic study of thermal degradation of sugar cane bagasse. Journal of Analytical and Applied Pyrolysis, 38, pp. 61-73, 1996 
[19] Tzamtzis, N., Pappa, A. \& Mourikis, A., The effect of $\left(\mathrm{NH}_{4}\right)_{2} \mathrm{HPO}_{4}$ and $\left(\mathrm{NH}_{4}\right)_{2} \mathrm{SO}_{4}$ on the composition of the volatile pyrolysis products of Pinus halepensis pine needles, Polymer Degradation and Stability, 66, pp. 5563, 1999

[20] Suardana, N.P.G, Ku, M.S. \& Lim, J.K., Effects of diammonium phosphate on the flammability and mechanical properties of biocomposites, Materials and Design, 32, pp. 1990-1999, 2011 